\title{
Comparison of resin modified glass ionomer cement and composite resin in class II primary molar restorations: a 2-year parallel randomised clinical trial
}

Dermata, A ; Papageorgiou, S N ; Fragkou, S ; Kotsanos, N

\begin{abstract}
AIM To compare the 2-year success rates of a Resin Modified Glass Ionomer Cement (RMGIC) with a composite resin in class II primary molar restorations. METHODS Healthy, cooperative children aged 4-7.5 years with at least one carious primary molar requiring a class II restoration were included in this parallel randomised trial and allocated on a 1:1 basis to composite resin (Z250, 3M ESPE) or RMGIC (Vitremer, 3M ESPE). Restorations were assessed semiannually up to 2 years clinically and radiographically using modified United States Public Health Service criteria, with the primary outcome being all-cause failure. Data were analysed per protocol by binomial linear regression with Relative Risks (RR) and their 95\% confidence intervals (CI). RESULTS 55 patients were randomly allocated to either group and 44 analysed at 2 years; with 49 teeth in the Z250 and 55 teeth in the Vitremer group. The all-cause failure rate for both materials was 3\% after 1 year (4 and 2\% for Z250 and Vitremer, respectively) and 16\% after 2 years (16\% for both Z250 and Vitremer). Overall, no difference between materials could be found at 2 years $(\mathrm{RR}=1.4 ; 95 \% \mathrm{CI} 0.8,2.4 ; \mathrm{P}=0.30)$. However, Vitremer was associated with more favourable gingival health compared to composite $(\mathrm{RR}=0.2 ; 95 \% \mathrm{CI} 0.1,0.9 ; \mathrm{P}=0.03)$, but also occlusal wear, which was observed exclusively for Vitremer. CONCLUSION No significant difference was found in the overall performance of the two materials, making them suitable for class II primary molar restorations, although RMGIC presented more pronounced occlusal wear of limited clinical importance after 2 years.
\end{abstract}

DOI: https://doi.org/10.1007/s40368-018-0371-7

Posted at the Zurich Open Repository and Archive, University of Zurich ZORA URL: https://doi.org/10.5167/uzh-169504

Journal Article

Accepted Version

Originally published at:

Dermata, A; Papageorgiou, S N; Fragkou, S; Kotsanos, N (2018). Comparison of resin modified glass ionomer cement and composite resin in class II primary molar restorations: a 2-year parallel randomised clinical trial. European Archives of Paediatric Dentistry, 19(6):393-401.

DOI: https://doi.org/10.1007/s40368-018-0371-7 


\title{
Comparison of resin modified glass ionomer cement and composite resin in class
}

\section{II primary molar restorations: a 2-year parallel randomized clinical trial.}

\author{
A. Dermata ${ }^{1} \cdot$ S.N. Papageorgiou ${ }^{2} \cdot$ S. Fragkou ${ }^{1} \cdot$ N. Kotsanos $^{1}$ \\ ${ }^{1}$ Department of Paediatric Dentistry, Dental School, Aristotle University of Thessaloniki \\ ${ }^{2}$ Clinic of Orthodontics and Pediatric Dentistry, Center of Dental Medicine, University of Zurich
}

Corresponding author: Anastasia Dermata; dermatasa@gmail.com.

Keywords resin modified glass ionomer $\bullet$ composite resin $\bullet$ restorations $\bullet$ primary molar $\bullet$ randomized clinical trial

Conflict of Interest: The authors declare that they have no conflict of interest.

Words in abstract: 250

Words in text: 3721 


\section{Abstract}

Aim To compare the two-year success rates of a Resin Modified Glass Ionomer Cement (RMGIC) with a composite resin in class II primary molar restorations.

Methods Healthy, cooperative children aged 4-7.5 years with at least one carious primary molar requiring a class II restoration were included in this parallel randomized trial and allocated on a 1:1 basis to composite resin (Z250, 3M ESPE) or RMGIC (Vitremer, 3M ESPE). Restorations were assessed semiannually up to 2 years clinically and radiographically using modified United States Public Health Service criteria, with the primary outcome being all-cause failure. Data were analyzed per protocol by binomial linear regression with Relative Risks (RR) and their 95\% Confidence Intervals (CI). Results 55 patients were randomly allocated to either group and 44 analyzed at two years; with 49 teeth in the Z250 and 55 teeth in the Vitremer group. The all-cause failure rate for both materials was 3\% after 1 year (4\% and 2\% for Z250 and Vitremer, respectively) and 16\% after 2 years (16\% for both Z250 and Vitremer). Overall, no difference between materials could be found at 2 years $(\mathrm{RR}=1.4 ; 95 \%$ $\mathrm{CI}=0.8,2.4 ; \mathrm{P}=0.30)$. However, Vitremer was associated with more favourable gingival health compared to composite $(\mathrm{RR}=0.2 ; 95 \% \mathrm{CI}=0.1,0.9 ; \mathrm{P}=0.03)$, but also occlusal wear, which was observed exclusively for Vitremer.

Conclusion No significant difference was found in the overall performance of the two materials, making them suitable for class II primary molar restorations, although RMGIC presented more pronounced occlusal wear of limited clinical importance after 2 years. 


\section{Introduction}

In addition to amalgam, which has traditionally been used to restore primary molars for over 150 years and is still widely used, other materials e.g. composite resin, glass ionomer cements, and compomers have been gradually introduced in clinical practice. The reasons for the continuing development and increased use of these materials in primary molar teeth included among others: allegations concerning the toxic side effects of amalgam to the patients and the ecosystem (Eley 1997), a growing demand for aesthetically pleasing restorations, and the recent tendency for a minimal intervention restorative approach (Hickel 1996). The selection of the best restorative material for posterior primary teeth remains a challenge for the clinician, as factors like the extent of the carious lesion, patient age, and patient cooperativeness (Mjör et al. 2002) have to be taken into account.

Composite resin restorations were first used for the restoration of carious lesions more than 50 years ago. As a material that fulfils aesthetic expectations, composites have become increasingly used instead of amalgam (Opdam et al. 2010) and remain a popular primary molar restoration material. Composite resin can be successfully used for primary molar Class I restorations (Hickel et al. 2005; Soncini et al. 2007), while a randomized controlled trial has also shown success of Class II composite restorations in primary teeth over a two-year period (Fuks et al. 2000). Despite the fact that composites show similar success rate to amalgam in the short terms, their success rate seems to decline in the long term. Loss of retention, marginal discolouration, and secondary caries are considered as the main reasons for failure in composite resin restorations, with these being attributed mainly to polymerization shrinkage (Fuks et al. 2000). Additionally, composite resin is considered to be a technique-sensitive material requiring a precise placement protocol with extended duration and its success may be compromised when tooth isolation or patient cooperation cannot be successfully achieved (Antony et al. 2008).

Glass ionomer cements were introduced in the early 1970s (Wilson and Kent 1972) and present a number of potential advantages such as fluoride $(\mathrm{F})$ release, chemical bonding to the tooth structure, and favourable biocompatibility. Despite their low fracture toughness and poor wear resistance (Hickel and Manhart 1999), GICs are regarded by some researchers as the restorative material of choice in the 
primary dentition (Mjör et al. 2002; Milsom et al. 2002). The addition of resin components greatly decreased setting time by utilizing light polymerization and improved the handling characteristics of glass ionomer cements, as well as the material's wear resistance and fracture toughness. Thus resinmodified glass ionomer cements (RMGIC) were introduced into general use in the early 1990's. The major advantages of glass ionomer cements, such as fluoride release, biocompatibility, and convenient thermal expansion or contraction properties, as well as physic-chemical bonding to tooth structure were retained (De Gee et al. 1996), resulting in a material far superior to conventional glass ionomer cements, with decreased moisture sensitivity compared to resins (Hübel and Mejàre 2003). Nicholson and Croll (1997) propagated that RMGIC could become a mainstream restorative material for paediatric dentistry, due to its promising clinical properties. However, clinical decision making must be based on critical appraisal of robust evidence from randomized clinical trials or systematic reviews thereof. There exists a single randomized trial (Sengul and Gurbuz 2015) that allocated 41 patients in need of Class II restoration in primary teeth to four different restorative materials and found no difference in failure rate between hybrid composite and RMGIC (Sengul and Gurbuz 2015). This trial however included a limited sample of about 10 patients per restorative material group, which might have influenced its results. Therefore, aim of the present randomized trial was to compare the in vivo success rate of RMGIC and composite resin used in children for Class II primary molar restoration over a period of 2 years.

\section{Materials and methods}

\section{Trial design and participants}

This was a two-group single-centre randomized clinical trial with parallel patient allocation to the composite resin and RMGIC group. Healthy (ASA I, II) and co-operative (Frankl 3,4) 4.0 to 7.5 yearold mostly Caucasian children with at least one first or second primary molar requiring a class II restoration were eligible to be included in the study. All the children were patients at the post-graduate

clinic in the Department of Paediatric Dentistry, Dental School, Aristotle University of Thessaloniki, Greece. The study protocol was ethically approved by the School's Research Ethics Committee (179/124-2012). Informed consent was obtained from the parent or guardian of the children participants 
included in the study before treatment. Children were randomly allocated to receive either composite resin (Z250, 3M ESPE Dental Products Co. St. Paul, MN) or RMGIC (Vitremer, 3M ESPE Dental Products Co. St. Paul, MN) restorations. The carious lesions should not have invaded the inner third of the dentin, as shown radiographically, and any teeth requiring multi-surface restorations were excluded.

\section{Intervention: restorative technique}

Restorations were placed by 6 trained and calibrated operators who were all 2nd or 3rd year postgraduate Paediatric Dentistry students. These operators had already been trained during their first year of postgraduate studies and were further trained for appropriate cavity shape and sizes on natural extracted primary molars. They were then evaluated by performing ten class II restorations on appropriate clinic patients prior to initiation of the study.

All the restorations were placed under local anaesthesia and rubber-dam isolation. Cavities were prepared with a small cylindrical high-speed diamond bur, while soft carious dentine was removed with the use of round, size 4, low-speed steel burs. A thin, 5mm width, steel matrix band was secured around the approximal surface with a wooden wedge suitable for primary molar restorations. Both Z250 and Vitremer were used in accordance with the manufacturer's instructions.

Restorations with Z250. After etching the enamel with 37\% phosphoric acid gel for 30 seconds, and the dentine for about 8 seconds, thorough rinsing and careful drying for 15 seconds were carried out, with care being taken not to overly dehydrate the dentin. A bonding agent (Adper Scotchbond XT, 3M ESPE, St.Paul, MN, USA) was then applied and light-cured for 10 seconds. The Z250 was incrementally applied in two stages, with each layer being light-cured for 20 seconds. The trimming and polishing of the restorations was performed with a conical Arkansas stone. After rubber-dam removal, the occlusion was checked and trimming was repeated if necessary.

Restorations with Vitremer. Following cavity preparation, the primer was applied for 30 seconds and light-cured for 10 seconds. The Vitremer powder and liquid dose was manually mixed, placed in the cavity with the recommended application tip and light-cured for 40 seconds. The restoration was 
then trimmed and polished as above. A finishing gloss was applied using a microbrush, gently blown and cured for 20 seconds. The occlusion was checked as above.

\section{Outcomes: assessment of restorations}

The primary outcome of this randomized trial was failure of the restoration, for any clinical reason. The clinical assessment of the restorations was made at baseline and semiannually, whereas the radiographic assessment was performed annually. All restorations were assessed by four experienced paediatric dentists and instructors in the Paediatric Dentirstry Clinic that were not involved in restoration placement and had been previously calibrated (Kendall's W=0.7 and 0.88). Accordance of these four assessors had been previously reached by discussing evaluation of 10 primary molar restorations until agreement was obtained. Subsequently, all assessors separately evaluated old class II restorations in 10 clinic patients.

All restorations were evaluated using a modification of the United States Public Health Service (USPHS) criteria (Cvar and Ryge 1971), covering: presence of the restoration, marginal integrity, proximal contacts, anatomical form (including occlusal wear), gingival health, and the presence of secondary caries, with criteria individually judged as A (Alpha), B (Bravo) or C (Charlie) (see Appendix). Any restoration graded as $\mathrm{C}$ by the examiners was considered as unacceptable and had to be replaced. The primary outcome of the trial was all-cause failure of the restoration (i.e. $\mathrm{C}$ for at least one criterion), while secondary outcomes included failure of each separate USPHS criterion.

\section{Sample size}

Sample size calculation was conducted a priori using the following assumptions: alpha of $5 \%$, beta of $20 \%$, baseline failure rate for the composite resin of $15 \%$, minimally important difference in the failure rate between materials of $25 \%$ (Casagrande et al. 2013), and use of a chi-square test. A total of 98 teeth (49 per group) was calculated to be required, which, after considering a median 2 primary molars treated per patient, resulted in the total requirement of 50 patients for this trial ( 25 patients in each group), which was rounded up to 55 patients to account for possible drop-outs. 


\section{Randomization / allocation concealment}

An unrestricted computer-generated list of random numbers was used to assign by central allocation through the clinic management patients to the two restoration materials. Each clinician was informed prior to placement of the restoration by a third person to which material was the patient allocated, and all Class II cavities of the patient's primary teeth were restored with the same material.

\section{Blinding}

Blinding of the six treatment providers was not possible, as the two materials differ both visually and in protocol. No measures to blind the patients were undertaken, but they were not informed about which material they received and both materials would seem visually similar to laypersons. The four outcome assessors were not told which material had a patient received, but they could probably perceive group allocation, due to their clinical expertise. After data collection a coded dataset with "group 1" and "group 2 " as designations for the two materials was prepared and handed to the data analyst, who performed blindly the statistical analysis. The code was broken after finalizing the analysis plan and exporting all results.

\section{Statistical methods}

Descriptive statistics were calculated as frequencies for all USPHS criteria and time-to-event (failure) for each restoration. Crude differences between the USPHS criteria assessment of the two groups were initially checked with Fisher exact tests. Afterwards, differences in the performance of restorations for each USPHS criterion separately and as overall all-cause failure (failure of at least one USPHS criterion) were assessed with generalized linear regression modelling for the binary family. In this, bivariable analyses for each outcome were fitted, taking into account the clustering of multiple restorations within a patient with robust standard errors, while reporting Relative Risks (RR) and the corresponding 95\% Confidence Intervals (CI). Failure here was defined as category B or C for all criteria. Additionally, the potentially significant confounding effects from the factors patient gender, age, tooth type, and jaw were 
controlled for by calculating adjusted RRs from multivariable models, following a pre-defined protocol (Weinberg 2013). Each confounder was inserted in a separate bivariable model for each outcome and confounders with $\mathrm{P}<0.2$ in this model, were included in a multivariable model with the randomized material. All analyses were run blindly per protocol in Stata SE 14.0 (Stata Corp, College Station, TX) with a two-sided $\mathrm{P} \leq 0.05$. No ancillary analyses for this trial were planned or performed.

\section{Results}

Recruitment, participant flow, and baseline data

A total of 65 patients were screened for eligibility in the Paediatric Dentistry Clinic between May 2012-May 2014. Fifty-five children met the inclusion criteria and were randomly allocated to receive either composite resin (Z250) or RMGIC (Vitremer) restorations (Figure 1). However, 7 patients (5 and 2 in the Z250 and Vitremer group, respectively) didn't show up for the placement appointment, so 48 patients (23 and 25 in the Z250 and Vitremer group, respectively) received the allocated restorations. A total of 113 (60 first and 52 second) primary molars were evaluated at the 12-month follow-up, while a total of 104 (58 first and 51 second) primary molars were evaluated at the 24-month follow-up. There were 8 drop-outs for the Z250 group and 2 drop-outs for the Vitremer group at the 6month follow-up. Another 2 restorations were not available for evaluation at the 12-month follow-up for the Vitremer group. Finally, 44 patients were followed up for two years, with 49 teeth in the Z250 and 55 teeth in the Vitremer group.

Fifty-five children ( 31 girls and 24 boys) met the inclusion criteria and were randomly allocated to receive either composite resin (Z250) or RMGIC (Vitremer) restorations (Table 1). The mean age of the children was $80.5 \pm 15.3$ months for the composite resin group and $81.0 \pm 16.0$ months for the RMGIC group (Table 1). In all, 124 Class II restorations were placed, 61 with Z250 and 63 with Vitremer. One Vitremer restoration had been lost at the 12-month follow-up while 3 Z250 restorations were absent at the 24 month evaluation (Table2).

\section{Outcomes and estimation}


The majority of the restorations examined semiannually up to 24 months were rated Alpha. For most of the parameters assessed, there were no statistically significant differences between the two groups.

Regarding marginal integrity, all restorations were evaluated as A at the 6-month follow-up. At the 12- and the 24-month evaluations, 2 and 5 Z250 restorations as opposed to 6 and 13 Vitremer restorations, respectively, were rated as B. The difference between the two groups was not statistically significant. The one and two year rating of the restorations for marginal integrity are further shown on Table 2. Regarding the contact point integrity, there was one $\mathrm{Z} 250$ restoration (2\%) rated as $\mathrm{C}$ at the 24months follow-up, while, $7 \%$ and $12 \%$ of the Vitremer restorations were rated B at the 12- and 24-month evaluation respectively. There were 2 Vitremer restorations rated as $\mathrm{C}$ at the 24 months evaluation. The 12- and 24-month ratings are further shown in Table 2.

Regarding the gingival health, there were statistically significant differences in favour of Vitremer both at the 12- and the 24-month evaluations and the data are presented in Table 2. Secondary caries however, was seen in 6 (13\%) Z250 and 4 (7\%) Vitremer restorations at the final follow-up. As seen in Table 2 together with further data for the 12- and the 24-month evaluation, the difference was not statistically significant. When the occlusal wear was evaluated, 4 and $12(22 \%)$ Vitremer restorations were rated as B at the 12-, and 24-month evaluation respectively. One (2\%) Vitremer restoration was rated as $\mathrm{C}$ at the 24-month evaluation. All the $\mathrm{Z} 250$ restorations were rated as A during the 24-month follow-up period. The difference was statistically significant (Table 2).

The cumulative all-cause failures after 2 years were $8(16 \%)$ for the Z250 and $9(16 \%)$ for the Vitremer restorations, equal for the two materials (Table 2). Tables 3a-3b provide the results of the univariable and multivariable regression as relative risks (RR) and their 95\% confidence intervals (CI). After taking into account clustering effects and confounding in the multivariable model, no statistically significant difference could be seen between the two materials for all-cause failure (i.e. failure of at least one USPHS criterion; $\mathrm{RR}=1.56 ; \mathrm{P}=0.20$ ). A trend close to significance was seen for higher failure of the contact point integrity criterion with Vitremer compared to Z250 ( $\mathrm{RR}=7.17 ; \mathrm{P}=0.07)$. On the other hand, teeth restored with Vitremer had significantly better gingival health compared to teeth restored with Z250, as seen by the corresponding criterion $(\mathrm{RR}=0.24 ; \mathrm{P}=0.03)$. Finally, occlusal wear could be 
perfectly predicted by the choice of material, since only teeth restored with Vitremer were graded as B or C.

\section{Discussion}

\section{Interpretation of findings}

The results of the present 2-year single-centre blinded randomized clinical trial indicate that no statistically significance difference in the overall performance (all-cause failure) of composite resin or RMGIC used for Class II primary molar restorations can be found, although differences in specific USPHS criteria seem to exist. Requirements for materials used for restoring primary dentition may differ from those for permanent teeth. Except for the extent of the carious lesion, the choice should take into consideration factors such as the age and cooperation of the patient while adjusting for the increasing aesthetic demands. In addition, the easier insertion technique and decreased chair time are regarded as advantages in a restorative material for primary teeth. Consequently, the selection of the appropriate restorative material for primary teeth remains a challenge for the clinician. Both composite resin and RMGIC are widely used for the restorations of primary molars (Mjör et al. 2002; Milsom et al. 2002).

While the annual failure rates of composite resin restorations in primary molars range between 0-15\% (Espelid et al. 1999; Honkala et al.), RMGICs show somewhat lower annual failure rates that range between 0.8-10\%) (Donly et al. 1999; Espelid et al. 1999; Hübel S and Mejàre 2003). In the prospective study of Folkesson et al. (1999) the failure rate in Vitremer restorations was $8.1 \%$ for the first year, $11.7 \%$ for the second and 19.8 for the third year. The most common reasons for failure were secondary caries and loss of retention. The factors possibly contributing to the clinical behaviour of these materials are the higher polymerization shrinkage of the composite resin, the better adhesion of the RMGI to the cavity walls and the fluoride release of the RMGI (Fuks et al. 2000). In the present study, the cumulative all-cause failures after 2 years were equal for the two materials, 8 (16\%) for the Z250 and 9 (16\%) for the Vitremer restorations.

The young age of the patients may contribute to increased failure rate. The lack of appropriate isolation or the limited cooperation of the patient may lead to a reduced quality of the restoration (Antony 
et al. 2008). In this study the children were relatively young. Nevertheless, local anaesthesia and a rubber-dam isolation were used for all the restorations, while uncooperative patients (Frankl 1,2) were excluded, reducing the influence of the young age factor in the results.

Composite resin is a popular restorative material for restoring carious lesions in primary molars. Its satisfactory adhesion, aesthetics and physicomechanical properties enable composites to be used in posterior teeth. Nevertheless, these materials require a longer working time and are regarded as technique sensitive, making their use more demanding for younger patients. The success rates of composite resin are comparable to amalgam in short term studies, but may be questioned in long term studies. Hse and Wei (1997) reported a failure rate of $1.7 \%$ of the hybrid composite Prisma TPH one year after placement, while Varpio (1985) reported a success rate for composites of $86 \%$ for the first year and a median survival rate of 32 months. Loss of retention is reported as one of the main disadvantages of the material (Fuks et al. 2000). In the present study, 3 Z250 restorations were lost at the 24 months evaluation, while one Vitremer restoration was lost at the 12 months evaluation, with no statistically significant difference between the two materials.

Poor marginal adaptation is also cited as a main cause of failure in composite resin. In the study of Granath et al. (1992), the main reasons for failure were marginal adaptation and discolouration at the margins. These findings are mainly related to polymerization shrinkage, which still remains a deficiency of the material (Fuks et al. 2000). However, in this study, marginal integrity was rated as A for $87 \%$ of the Z250 restoration. The corresponding rate for Vitremer was $72 \%$, with the difference between the two materials not being statistically significant.

Studies on the use of composite resin highlight secondary caries as an important reason for restoration replacement (Fuks et al. 2000). Although greatly reduced within a week or two after mixing, fluoride release by the RMGIC is regarded as continuous, possibly resulting in a cariostatic effect. Donly et al. (1999) found that Vitremer presented with less demineralization than amalgam in the proximal surface of class II primary molar restorations and this was further supported by intraoral findings (Kotsanos 2001). Fluoride release values for RMGIC range from $50-600 \mathrm{mg} / \mathrm{cm} 2$ and are significantly higher than those for composite resin which range from 0-10mg/cm2 (Hickel 1996). This indicates that 
RMGIC might be more appropriate for children with high caries susceptibility (Fuks et al. 2000). In the present study, secondary caries was the main reason of failure. In particular, 2(4\%) and 6(13\%) teeth with Z250 presented secondary caries at the 12 and 24 months evaluations respectively, in comparison with 0 and 4 (7\%) teeth in the RMGIC group, with the difference between the two materials not being statistically significant.

One criterion that showed a significant difference between resin and RMGIC restorations was gingival health. A higher percentage of composite restorations presented with bleeding on probing, both at the 12 months and the 24-months recall visit. The generalised linear model also indicated a lower relative risk of poor gingival health using Vitremer rather than Z250. According to the study of Santos et al. (2007), RMGIC had a stronger effect on the subgingival biofilm composition than composite resin. The study of Atieh (2008), reported that open-sandwich restorations exposing Vitremer in their proximal aspect were conducive to statistically significantly better gingival health in comparison with preformed metal crowns.

Light-cured materials are associated with uncured layers of resin in deeper cavities. Incremental placement of the material is proposed to overcome this drawback. Vitremer is a so called 'tri-cure' RMGIC, the third curing procedure being initiated with the mixing of the powder and liquid and continuing in the dark, thus allowing the curing of the material in the deeper layers. While wear resistance and fracture toughness have been improved in comparison to conventional glass ionomer cement (Mitra and Kedrowski 1994; De Gee et al. 1996), clinically noticeable occlusal wear remains as a disadvantage in Vitremer and possibly with any sizeable RMGIC restoration (Kotsanos and Arizos 2011). Regarding the occlusal wear in the present study, 12 (22\%) of the Vitremer restorations were rated as $\mathrm{B}$ and $1(2 \%)$ as $\mathrm{C}$ at the 24 months assessment, while all $\mathrm{Z} 250$ restorations were rated as $\mathrm{A}$. The difference between the two groups was statistically significant. However, restorations rated as B for occlusal wear by Cvar and Ryge criteria (i.e. no exposed cut tooth structure) do not probably bear clinical significance for primary molars.

\section{Limitations}


The fact that the present study was conducted in a single centre might have limited the variability of its sample. As however, the university's Paediatric Dentistry Clinic receives a large number patients of variable age, nationality, socioeconomic level, and dental needs, this contributes to the sample's diversity. Furthermore, blinding of treatment providers and outcomes assessors was impractical to be strictly implemented, since they were experienced clinicians calibrated in the handling/assessing of both materials. Finally, as only cooperative children were included in the trial, the results of the trial might not be directly extrapolated to non-cooperative children.

\section{Generalizability}

The results of the present trial are applicable to the majority of healthy co-operative children of mostly Caucasian descent, aged 4.0-7.5 years old with at least one primary molar in need of Class II restoration.

\section{Conclusions}

Both Vitremer and Z250 presented acceptable clinical behaviour at the 24 months follow-up. The overall success rate for both materials was $84 \%$ after two years. There were no statistically significant differences in any parameters other than gingival health (in favour of Vitremer), and occlusal wear (in favour of Z250).

Ethical approval: All procedures performed in studies involving human participants were in accordance with the ethical standards of the institutional and/or national research committee and with the 1964 Helsinki declaration and its later amendments or comparable ethical standards. 


\section{References}

Antony K, Genser D, Hiebinger C, Windisch F. Longevity of dental amalgam in comparison to composite materials. GMS Health Technol Assess 2008;4:Doc12.

Atieh M. Stainless steel crown versus modified open-sandwich restorations for primary molars: a 2-year randomized clinical trial. Int J Paediatr Dent. 2008;18(5):325-32.

Casagrande L, Dalpian DM, Ardenghi TM et al. Randomized clinical trial of adhesive restorations in primary molars. 18-month results. Am J Dent. 2013;26(6):351-5.

Cvar J, Ryge G. Criteria for the clinical evaluation of dental restorative materials. US Public Health Service Publ. 1971;790-244.

De Gee AJ, van Duinen RN, Werner A, Davidson CL. Early and long-term wear of conventional and resin-modifies glass ionomers. J Dent Res. 1996;75(8):1613-9.

Donly KJ, Segura A, Kanellis M, Erickson RL. Clinical performance and caries inhibition of resinmodified glass ionomer cement and amalgam restorations. J Am Dent Assoc. 1999;130(10):145966.

Eley BM. The future of dental amalgam: a review of the literature. Part 6: Possible harmful effects of mercury from dental amalgam. Br Dent J. 1997;182(12):455-9.

Espelid I, Tveit AB, Tornes KH, Alvheim H. Clinical behaviour of glass ionomer restorations in primary teeth. J Dent. 1999;27(6):437-42.

Folkesson UH, Andersson-Wenckert IE, van Dijken JWV. Resin-modified glass ionomer cement restorations in primary molars. Swed Dent J. 1999;23(1):1-9.

Fuks AB, Araujo FB, Osorio LB, Hadani PE, Pinto AS. Clinical and radiographic assessment of Class II esthetic restorations in primary molars. Pediatr Dent. 2000;22(5):479-85.

Granath L, Schröder U, Sundin B. Clinical evaluation of preventive and class-I composite resin restorations. Acta Odontol Scand. 1992;50(6):359-64.

Hickel R, Kaaden C, Paschos E, Buerkle V, García-Godoy F, Manhart J. Longevity of occlusallystressed restorations in posterior primary teeth. Am J Dent. 2005;8(3):198-211. 
Hickel R, Manhart J. Glass-ionomers and compomers in pediatric dentistry; in Davidson, C.L. and Mjor, I.A. (eds): Advances in glass-ionomer cements. Quintessence Publishing, pp. 201-226, 1999.

Hickel R. Glass ionomers, cermets, hybrid ionomers and compomers-(long-term) clinical evaluation. Trans Acad Dent Mater. 1996;9:105-29.

Honkala E, Behbehani J, Ibricevic H, Kerosuo E, Al Jame G. The atraumatic restorative treatment (ART) approach to restoring primary teeth in a standard dental clinic. Int J Paediatr Dent. 2003;13(3):17279.

Hse KMY, Wei SHI: Clinical evaluation of compomer in primary teeth: 1 year results. J Am Dent Assoc. 1997;128(8):1088-96.

Hübel S, Mejàre S. Conventional versus resin-modified glass-ionomer cement for Class II restorations in primary molars. A 3-year clinical study. Int J Paed Dent. 2003;13(1):2-8.

Kotsanos N, Arizos S. Evaluation of a resin modified glass ionomer serving both as indirect pulp therapy and as restorative material for primary molars. Eur Arch Paediatr Dent. 2011;12(3):170-5.

Kotsanos N. An intraoral study of caries induced on enamel in contact with fluoride-releasing restorative materials. Caries Res. 2001;35(3):200-4.

Milsom K M, Tickle M, Blinkhorn A. The prescription and relative outcomes of different materials used in general dental practice in the north west region of England to restore the primary dentition. $\mathrm{J}$ Dent. 2002;30(2-3):77-82.

Mitra SB, Kedrowski BL. Long-term mechanical properties of glass ionomers. Dent Mater. 1994;10(2):78-82.

Mjör IA, Dahl JE, Moorhead JE. Placement and replacement of restorations in primary teeth. Acta Odontol Scand. 2002;60(1):25-28.

Nicholson J, Croll TP. Glass-ionomer cements in restorative dentistry. Quintessence Int. 1997;28(11):705-14.

Opdam NJ, Bronkhorst EM, Loomans BA, Huysmans MC. 12-year survival of composite vs. amalgam restorations. J Dent Res. 2010;89(10):1063-7. 
Santos VR, Lucchesi JA, Cortelli SC et al. Effects of glass ionomer and microfilled composite subgingival restorations on periodontal tissue and subgingival biofilm: a 6-month evaluation. $\mathrm{J}$ Periodontol. 2007;78(8):1522-8.

Soncini JA, Meserejian NN, Trachtenberg F, Tavares M, Hayes C. The longevity of amalgam versus compomer/ composite restorations in posterior primary and permanent teeth: Findings from the New England Children's Amalgam Trial. J Am Dent Assoc. 2007;138(6):763-72.

Varpio M. Proximocclusal composite restorations in primary molars: a six-year follow-up. ASDC J Dent Child. 1985;52(6):435-40.

Weinberg S. Variable Selection. In: Weisberg S (ed), editor. Applied Linear Regression, 4th edition. John Wiley and Sons, pp. 227-44, 2013.

Wilson AD, Kent BE. A new transluscent cement for dentistry. The glass ionomer cement. Br Dent J. 1972;132(4):133-5. 


\section{Figure legends}

Fig. 1. Flow diagram for the identification, randomization, and analysis of patients in the trial.

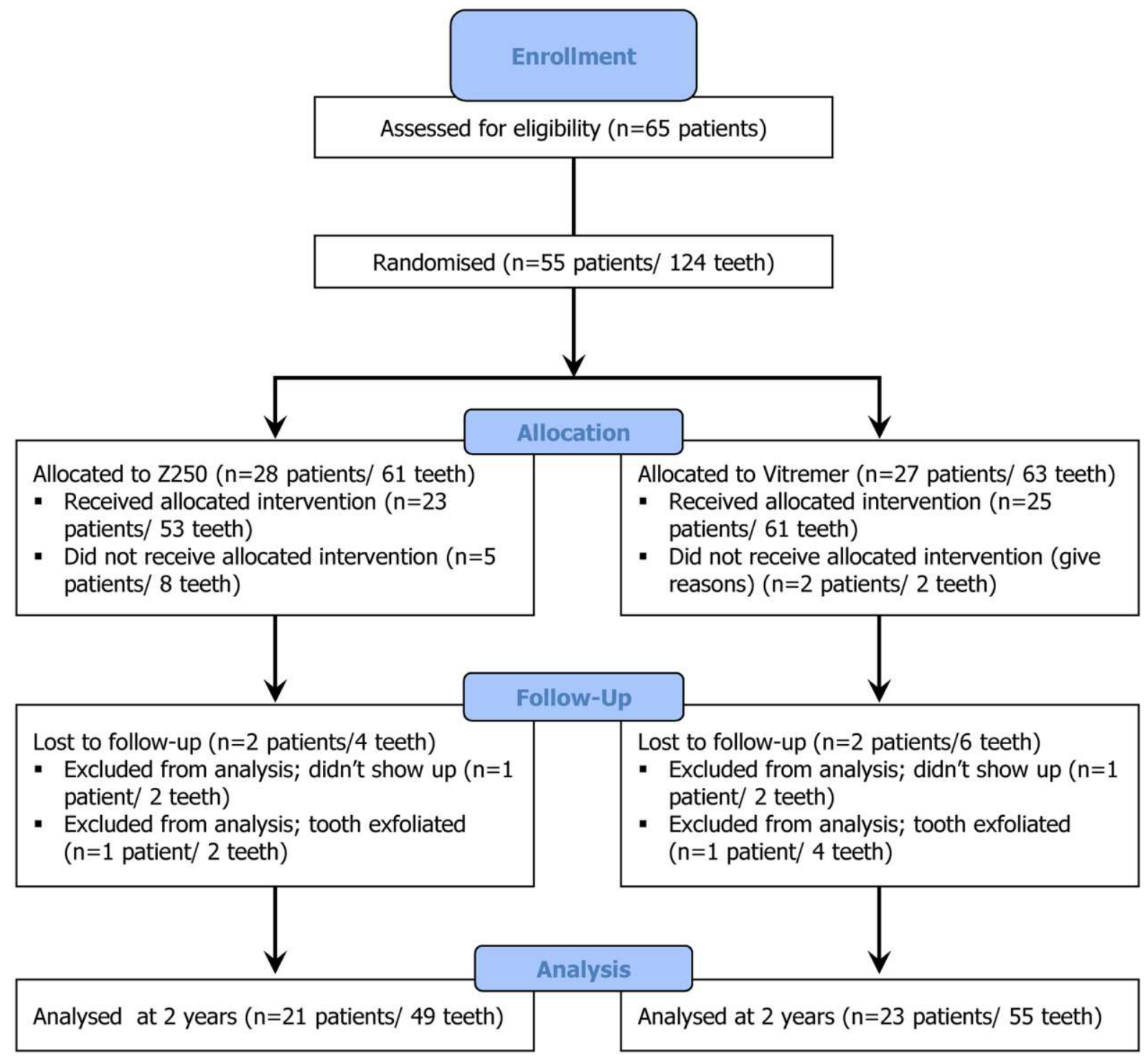




\section{Tables}

Table 1 Demographic characteristics of randomized patients

\begin{tabular}{|l|l|l|l|l|l|l|}
\hline \multicolumn{3}{|c|}{ Randomized } & \multicolumn{3}{l|}{ Analysed at 24 months } \\
\hline & Overall & Z250 & Vitremer & Overall & Z250 & Vitremer \\
\hline $\mathrm{N}$ & 55 & 28 & 27 & 44 & 21 & 23 \\
\hline Male - n (\%) & $24(44 \%)$ & $12(43 \%)$ & $12(44 \%)$ & $19(43 \%)$ & $8(38 \%)$ & $11(48 \%)$ \\
\hline Female - n (\%) & $31(56 \%)$ & $16(56 \%)$ & $15(56 \%)$ & $25(57 \%)$ & $13(62 \%)$ & $12(52 \%)$ \\
\hline & & & & & & \\
\hline Age - mean (SD) & $80.7(15.5)$ & $80.5(15.3)$ & $81.0(16.0)$ & $78.9(14.9)$ & $78.6(15.1)$ & $79.3(15.0)$ \\
\hline & & & & & & \\
\hline Restorations/patient & & & & & & \\
\hline One - n (\%) & $17(31 \%)$ & $8(29 \%)$ & $9(33 \%)$ & $12(27 \%)$ & $5(24 \%)$ & $7(30 \%)$ \\
\hline Two - n (\%) & $22(40 \%)$ & $12(43 \%)$ & $10(37 \%)$ & $18(41 \%)$ & $9(43 \%)$ & $9(39 \%)$ \\
\hline Three - n (\%) & $5(9 \%)$ & $3(11 \%)$ & $2(7 \%)$ & $4(9 \%)$ & $2(10 \%)$ & $2(9 \%)$ \\
\hline Four - n (\%) & $8(15 \%)$ & $5(18 \%)$ & $3(11 \%)$ & $7(16 \%)$ & $5(24 \%)$ & $2(9 \%)$ \\
\hline Five - n (\%) & $2(4 \%)$ & $0(0 \%)$ & $2(7 \%)$ & $2(5 \%)$ & $0(0 \%)$ & $2(9 \%)$ \\
\hline Six - n (\%) & $1(2 \%)$ & $0(0 \%)$ & $1(4 \%)$ & $1(2 \%)$ & $0(0 \%)$ & $1(4 \%)$ \\
\hline$S D$ sta)
\end{tabular}

$S D$ standard deviation 
Table 2 Assessment of the restorations using the USPHS criteria

\begin{tabular}{|c|c|c|c|c|c|c|c|c|c|}
\hline \multirow{2}{*}{ Criterion } & & \multicolumn{4}{|l|}{12 months } & \multicolumn{4}{|l|}{24 months } \\
\hline & & $\mathbf{A}$ & B & $\mathbf{C}$ & $\mathbf{P}^{*}$ & $\mathbf{A}$ & B & $\mathbf{C}$ & $\mathbf{P}^{*}$ \\
\hline \multirow{2}{*}{ 1. Restoration presence } & $\mathrm{Z} 250$ & $54(100 \%)$ & - & $0(0 \%)$ & 1.00 & $46(94 \%)$ & - & $3(6 \%)$ & 0.34 \\
\hline & Vitremer & $58(98 \%)$ & - & $1(2 \%)$ & & $54(98 \%)$ & - & $1(2 \%)$ & \\
\hline \multirow{2}{*}{ 2. Marginal Integrity } & $\mathrm{Z} 250$ & $52(96 \%)$ & $2(4 \%)$ & $0(0 \%)$ & 0.27 & $40(87 \%)$ & $5(11 \%)$ & $1(2 \%)$ & 0.21 \\
\hline & Vitremer & $52(90 \%)$ & $6(10 \%)$ & $0(0 \%)$ & & $39(72 \%)$ & $13(24 \%)$ & $2(4 \%)$ & \\
\hline \multirow{2}{*}{ 3. Integrity of contact point } & $\mathrm{Z} 250$ & $54(100 \%)$ & $0(0 \%)$ & $0(0 \%)$ & 0.12 & $45(98 \%)$ & $0(0 \%)$ & $1(2 \%)$ & 0.03 \\
\hline & Vitremer & $54(93 \%)$ & $4(7 \%)$ & $0(0 \%)$ & & $44(85 \%)$ & $6(12 \%)$ & $2(4 \%)$ & \\
\hline \multirow[t]{2}{*}{ 4. Gingival health } & $\mathrm{Z} 250$ & $46(85 \%)$ & $8(15 \%)$ & - & 0.002 & $34(74 \%)$ & $12(26 \%)$ & - & 0.005 \\
\hline & Vitremer & $58(100 \%)$ & $0(0 \%)$ & - & & $51(94 \%)$ & $3(6 \%)$ & - & \\
\hline \multirow[t]{2}{*}{ 5. Occlusion } & $\mathrm{Z} 250$ & $54(100 \%)$ & - & $0(0 \%)$ & - & $46(100 \%)$ & - & $0(0 \%)$ & - \\
\hline & Vitremer & $58(100 \%)$ & - & $0(0 \%)$ & & $54(100 \%)$ & - & $0(0 \%)$ & \\
\hline \multirow[t]{2}{*}{ 6. Secondary caries } & $\mathrm{Z} 250$ & $52(96 \%)$ & - & $2(4 \%)$ & 0.23 & $41(87 \%)$ & - & $6(13 \%)$ & 0.51 \\
\hline & Vitremer & $58(100 \%)$ & - & $0(0 \%)$ & & $50(93 \%)$ & - & $4(7 \%)$ & \\
\hline \multirow[t]{2}{*}{ 7. Occlusal wear } & $\mathrm{Z} 250$ & $54(100 \%)$ & $0(0 \%)$ & $0(0 \%)$ & 0.12 & $46(100 \%)$ & $0(0 \%)$ & $0(0 \%)$ & $<0.001$ \\
\hline & Vitremer & $54(93 \%)$ & $4(7 \%)$ & $0(0 \%)$ & & $41(76 \%)$ & $12(22 \%)$ & $1(2 \%)$ & \\
\hline \multirow[t]{3}{*}{$\begin{array}{l}\text { Cumulative all-cause } \\
\text { failure }\end{array}$} & & \multicolumn{2}{|l|}{ No failure } & Failure & $\mathbf{P}^{*}$ & \multicolumn{2}{|l|}{ No failure } & Failure & $\mathbf{P}^{*}$ \\
\hline & $\mathrm{Z} 250$ & \multicolumn{2}{|l|}{$52(96 \%)$} & $2(4 \%)$ & 0.61 & \multicolumn{2}{|l|}{$46(84 \%)$} & $9(16 \%)$ & 1.00 \\
\hline & Vitremer & \multicolumn{2}{|l|}{$58(98 \%)$} & $1(2 \%)$ & & \multicolumn{2}{|l|}{$41(84 \%)$} & $8(16 \%)$ & \\
\hline
\end{tabular}

* P value from Fisher's exact test 
Table 3a

Results of the univariable binary regression on factors associated with failure criteria

\begin{tabular}{|c|c|c|c|c|c|c|c|c|c|c|c|c|c|c|}
\hline & All-cause failur & & 1. retention & & 2. marginal int & grity & 3. contact poin & tegrity & 4. secondary $\mathrm{c}$ & & 6. gingival hea & & 7. occlusal wea & \\
\hline Material & RR (95\% CI) & $\mathbf{P}$ & $\operatorname{RR}(95 \% \mathrm{CI})$ & $\mathbf{P}$ & RR (95\% CI) & $\mathbf{P}$ & RR (95\% CI) & $\mathbf{P}$ & RR $(95 \% \mathrm{CI})$ & $\mathbf{P}$ & RR $(95 \%$ CI) & $\mathbf{P}$ & RR (95\% CI) & $\mathbf{P}$ \\
\hline Z250 & Referent & & Referent & & Referent & & Referent & & Referent & & Referent & & Referent & \\
\hline Vitremer & $\begin{array}{l}1.56 \\
(0.79,3.09)\end{array}$ & 0.20 & $\begin{array}{l}0.32 \\
(0.03,3.70)\end{array}$ & 0.36 & $\begin{array}{l}2.42 \\
(0.76,7.68)\end{array}$ & 0.13 & $\begin{array}{l}7.75 \\
(0.90,66.60)\end{array}$ & 0.06 & $\begin{array}{l}0.65 \\
(0.15,2.77)\end{array}$ & 0.56 & $\begin{array}{l}0.24 \\
(0.06,0.97)\end{array}$ & 0.05 & $\begin{array}{l}\text { Predicts } \\
\text { perfectly }\end{array}$ & $\mathrm{NC}$ \\
\hline
\end{tabular}

$R R$ relative risk, $C I$ confidence interval, $N C$ not calculable 
Table 3b Results of the univariable binary regression on factors associated with failure criteria (please check the lit on this point)

\begin{tabular}{|c|c|c|c|c|c|c|c|c|c|c|c|c|c|}
\hline \multirow[b]{2}{*}{ Factor } & \multirow[b]{2}{*}{ Category } & \multicolumn{2}{|l|}{ All-cause failure } & \multicolumn{2}{|l|}{ 1. retention } & \multicolumn{2}{|c|}{ 2. marginal integrity } & \multicolumn{2}{|c|}{ 3. contact point integrity } & \multicolumn{2}{|c|}{ 4. secondary caries } & \multicolumn{2}{|l|}{ 6. gingival health } \\
\hline & & RR (95\%) & $\mathbf{P}$ & RR (95\%) & $\mathbf{P}$ & RR (95\%) & $\mathbf{P}$ & RR (95\%) & $\mathbf{P}$ & $\operatorname{RR}(95 \%)$ & $\mathbf{P}$ & RR (95\%) & $\mathbf{P}$ \\
\hline Material & $\mathrm{Z} 250$ & Referent & & Referent & & Referent & & & & & & Referent & \\
\hline & Vitremer & $1.36(0.76,2.44)$ & 0.30 & $00.28(0.02,4.16)$ & 0.36 & $2.32(0.83,6.50)$ & 0.11 & $7.17(0.85,60.47)$ & 0.07 & $0.69(0.15,3.11)$ & 0.63 & $0.24(0.07,0.86)$ & 0.03 \\
\hline Gender & Male & NT & NT & NT & NT & $1.73(0.66,4.54)$ & 0.27 & NT & NT & NT & NT & NT & NT \\
\hline & Female & Referent & & & & & & & & & & & \\
\hline Age & Per year & $0.98(0.96,1.00)$ & 0.13 & $1.07(0.98,1.16)$ & 0.12 & $0.97(0.93,1.02)$ & 0.23 & $1.05(1.01,1.10)$ & 0.02 & $0.97(0.92,1.01)$ & 0.14 & $0.93(0.89,0.97)$ & 0.001 \\
\hline Jaw & Upper & $0.71(0.40,1.28)$ & 0.26 & NT & NT & NT & NT & NT & NT & NT & NT & NT & NT \\
\hline & Lower & Referent & & & & & & & & & & & \\
\hline Molar & $2^{\text {nd }}$ & NT & NT & NT & NT & $1.82(0.89 .3 .71)$ & 0.10 & NT & NT & NT & NT & NT & NT \\
\hline & $1^{\text {st }}$ & Referent & & & & Referent & & & & & & & \\
\hline
\end{tabular}

$R R$ relative risk, $C I$ confidence interval, $N T$ not tested. 


\section{Supplementary material}

Appendix Details of the modification of USPHS criteria used for the assessment of restorations

\begin{tabular}{|c|c|c|c|}
\hline Criterion & A (alpha) & B (bravo) & C (charlie) \\
\hline $\begin{array}{l}\text { Presence of the } \\
\text { restoration }\end{array}$ & Presence of restoration & (2) & Absence of restoration \\
\hline Marginal Integrity & Absence of crevice along the margin & $\begin{array}{l}\text { No visual defect, crevice along the margin detectable by } \\
\text { probe. The dentin and/or the base is not exposed and the } \\
\text { restoration is not mobile. }\end{array}$ & $\begin{array}{l}\text { Visual crevice along the margin. The } \\
\text { explorer penetrates crevice defect } \\
\text { extended to the dento-enamel } \\
\text { junction. }\end{array}$ \\
\hline Contact surface & $\begin{array}{l}\text { There is a tight contact through which dental } \\
\text { floss is inserted with difficulty }\end{array}$ & $\begin{array}{l}\text { Contact point with the adjacent tooth exists but there is no } \\
\text { resistance when flossing }\end{array}$ & No contact point is detected \\
\hline Gingival Health & no bleeding on probing & bleeding on probing & spontaneous bleeding \\
\hline Secondary Caries & No secondary caries detected & 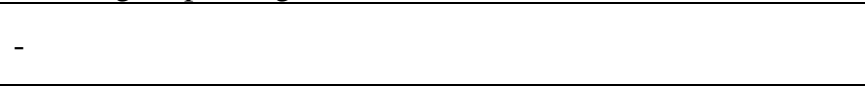 & $\begin{array}{l}\text { Presence of secondary caries either } \\
\text { clinically or radiographically }\end{array}$ \\
\hline $\begin{array}{l}\text { occlusal wear } \\
\text { (anatomical form) }\end{array}$ & $\begin{array}{l}\text { The restoration is a continuation of the } \\
\text { anatomic form of the tooth. }\end{array}$ & $\begin{array}{l}\text { Evident surface concavity. However the dentin or base is not } \\
\text { exposed }\end{array}$ & $\begin{array}{l}\text { The loss of restorative substance is } \\
\text { such that a surface concavity is } \\
\text { evident and the base and/or dentin is } \\
\text { exposed }\end{array}$ \\
\hline
\end{tabular}

